\title{
䇏证 CEREUS
}

\section{A SEGURANÇA PÚBLICA EM GURUPI}

SILVA, Jhéssika Gomes da ${ }^{1}$ DISCONZI, Verônica Silva do Prado ${ }^{2}$; SILVA, Fábio Araújo³.

\section{RESUMO}

O presente artigo tem por objetivo abordar a polêmica matéria da segurança pública na atualidade, tendo em vista a sensação de insegurança que se instaurou em todos os lugares, não mais apenas nas comunidades carentes abandonadas pelas políticas públicas. Tratar-se-á precisamente com relação à cidade de Gurupi, Estado do Tocantins, localidade onde os índices têm assustado aos moradores do município. Considerando a amplitude do tema proposto, necessário se mostra o alerta quanto à necessidade de debatê-lo com maior precisão e qualificação em todos os setores da vida em comunidade, a fim de se encontrar novos paradigmas para orientar a criação e aprimoramento das políticas públicas capazes de pelo menos reduzir este índice exorbitante de criminalidade. Buscou-se reunir elementos

\footnotetext{
${ }^{1}$ Acadêmica do curso de direito do Centro Universitário UNIRG, Gurupi - TO.

2 Docentes do Curso de direito do Centro Universitário UnirG, Gurupi-TO. E-mail: fabiosilva2020@yahoo.com.br
} 
para a construção deste trabalho científico por meio de pesquisa bibliográfica acerca da problemática da segurança pública de um modo geral e o levantamento de dados sobre a situação local da criminalidade em Gurupi. Utilizando-se do método dedutivo a pesquisa inicia elencando a previsão constitucional à segurança, passando à análise das principais normas sobre o assunto, a sua constituição, etc. Ato contínuo se expõe a questão atual de Gurupi, com o demonstrativo de dados oficiais da Polícia Militar do Estado do Tocantins. Por fim, a apresentação das medidas paliativas tomadas em prol da segurança pública, bem como a indicação de políticas públicas visando dar mais conforto aos cidadãos amedrontados.

Palavras chave: Segurança Pública; Gurupi-TO; Responsabilidade Estatal.

\section{SAFETY IN PUBLIC GURUPI}

\section{ABSTRACT}

This article aims to address the controversial issue of public security at the present time, given the sense of insecurity which arose everywhere, not just in poor communities abandoned by public policies. Treat yourself will precisely with respect to the city of Gurupi, State of Tocantins, location where the indices have scared the residents of the municipality. Considering the scope of the proposed theme, need to show the warning about the need to discuss it with greater precision and qualification in all sectors of community life in order to find new paradigms to guide the creation and improvement of public policies capable at least reduce this outrageous crime rate. He attempted to gather elements for the construction of this scientific work by means of literature about public safety issues in general and the survey data on local crime situation 
in Gurupi. Using the deductive method to research and starts elencando the constitutional provision to safety through the analysis of key standards sound matter, its constitution, etc. Subsequently, it exposes the current issue of Gurupi, with the statement of official data of Police of Tocantins State Military. Finally, the presentation of the remedial measures taken for the sake of public safety, as well as an indication of public policies to give more comfort to frightened citizens.

Keywords: Public Security; Gurupi-TO; State responsibility 


\section{INTRODUÇÃO}

Nos últimos anos, a questão da segurança pública tem chamado a atenção dos mais variados setores em comunidade, por afetar a sociedade em geral, sendo que, diante da sua abrangência,

Diante da abrangência de seu alcance, a segurança pública tornou-se um dos temas mais debatidos por especialistas e pela sociedade em geral, por se tornar um dos problemas de maior incidência, assumindo cerca de noventa por cento das notícias vinculadas nos jornais nacionais.

No país inteiro, a sensação de insegurança tem afetado as cidades mais populosas e outras nem tanto, sendo este fator determinante para o levantamento de discussões dos mecanismos públicos para o combate da criminalidade, mais especificamente no tocante às formas de prevenção de crimes. (SOUZA, 2015, p.01)

Tanto é assim que a "violência e o descontrole da criminalidade afetam a todos, desde o cidadão mais simples ao mais culto, ocorrem tanto no ambiente das favelas aos condomínios mais luxuosos." (SOUZA, 2015, p.01)

Infelizmente, a situação local acompanha os altos índices de violência nacional. Da análise dos dados e estatísticas a serem apresentadas na presente pesquisa jurídica, denota-se que a situação tem sido cada vez mais preocupante, merecendo atenção das autoridades competentes.

Conforme se demonstrará, há um aumento significativo das taxas de criminalidade, o que faz com que a sociedade sinta-se insegura nas vias públicas e também em suas próprias residências, não mais se restringindo aos horários noturnos, como antigamente. Não há por parte da população a sensação de segurança nem mesmo a luz do dia.

Dentre vários os problemas relacionados à segurança pública temos: a superpopulação nos presídios; as fugas; o aumento de atos inflacionais, ou seja, condutas típicas cometidas por menores; a violência policial; a falta de recursos para melhorar o sistema, devido a inúmeras corrupções; o aumento do crime de tráfico, que induz de forma camuflada a prática de outros delitos, dentre muitos outros fatores. 


\section{MATERIAIS E MÉTODOS}

A pesquisa jurídica que aborda a situação da segurança pública em Gurupi, Estado do Tocantins, compreende para sua realização, o uso de materiais bibliográficos, consistentes nas teorias que preveem o direito à segurança, bem como no levantamento de noticiários e dados policiais referentes à situação fática da localidade analisada.

São usadas também as legislações aplicáveis à segurança, além de materiais complementares quais sejam: entrevistas, livros, doutrinas e entendimentos jurisprudenciais recentes.

Para tanto, utilizar-se-á os ditames do método dedutivo de ensino, partindo-se das premissas gerais da segurança pública até se concluir sobre a problemática da segurança em Gurupi, especificamente.

\section{DIREITO CONSTITUCIONAL À SEGURANÇA PÚBLICA}

\subsection{DEFINIÇÃO DE SEGURANÇA PÚBLICA}

Antes de analisar o atual estado da segurança pública na cidade de Gurupi-TO, é importante elencar alguns aspectos iniciais acerca desse tema de grande relevância jurídica e social.

Nas sociedades em que a democracia é exercida plenamente, é a segurança pública 0 meio de salvaguardar o exercício pleno da cidadania e dos direitos individuais de todos os cidadãos. Seguindo esse raciocínio, o que se percebe é que a segurança não é oposta a liberdade e sim o instrumento para garantia de seu exercício. (SANTOS, 2006, p.1)

Objetivamente falando, a segurança é um direito fundamental difuso que todos os indivíduos têm de se sentirem protegidos pelo Estado, por meio das políticas públicas capazes de garantir a segurança com a eficácia que exige. (SOUZA, 2015, p.1)

De forma simplificada, a segurança é conceituada como sendo "a qualidade ou o estado de estar seguro". (QUE CONCEITO, 2016) 
Sob a perspectiva jurídica, segurança está atrelada ao sentido de proteção, garantia e estabilidade da pessoa ou da situação em que ela está inserida. (AFONSO, 2003, p.635)

Através

dessa definição, conclui-se que a segurança refere-se a um sentimento de não se sentir vulnerável no meio social em que vive, direito constitucional garantido a todo cidadão brasileiro por meio da Carta Cidadã de 1988.

\subsection{A SEGURANÇA PÚBLICA NA CONSTITUIÇÃO FEDERAL DE 1988}

Promulgada em 5 (cinco) de outubro de 1988, a Constituição Federal do Brasil, ao instituir o Estado democrático de direito, disciplinou a segurança pública já no seu artigo 5ํㅜㅇ, dispondo que "todos são iguais perante a lei, sem distinção de qualquer natureza, garantindo-se aos brasileiros e aos estrangeiros residentes no País a inviolabilidade do direito à vida, à liberdade, à igualdade, à segurança e à propriedade".

Encontra previsão ainda no artigo 6ำ ao dispor que a segurança pública é um dos direitos sociais dos cidadãos brasileiros.

Ao serem disciplinados os direitos sociais em um capítulo especifico fica evidente que tais direitos possuem condição de direitos fundamentais, haja vista que nas constituições anteriores os direitos sociais estavam disciplinados dentro do capítulo da ordem econômica e social, sendo reconhecidos apenas em caráter programático. (SARLET, 2012, p.66)

Após classificar a segurança pública como um objetivo e direito fundamental dos cidadãos brasileiros já nos seus primeiros capítulos, a Carta Magna voltou a tratar sobre o tema a partir do seu artigo 144, em um capítulo específico sobre a segurança pública, o qual estabelece em seu caput que "a segurança pública, dever do Estado, direito e responsabilidade de todos, é exercida para a preservação da ordem pública e da incolumidade das pessoas e do patrimônio".

Conforme determina o mesmo dispositivo de lei, essa obrigação ficou a cargo dos seguintes órgãos públicos: polícia federal, polícia ferroviária federal, polícia rodoviária federal, policias civis; militares e corpos de bombeiros militares. (CF, art. 144) 
Ao definir a segurança pública como um direito social, o constituinte de 1988 conferiu ao Estado a obrigação de garantir aos cidadãos 0 direito a integridade física, psíquica e moral para que possam viver livremente e com dignidade. (SOUZA, 2015, p.1)

\subsection{OS AGENTES DE PROMOÇÃO DA SEGURANÇA PÚBLICA}

Tendo em vista a relevância da força policial para a sociedade, a Constituição Federal tratou de delimitar e estabelecer qual a função de cada ente federativo para a garantia da segurança pública, ficando a cargo das mais variadas polícias.

A polícia federal, disciplinada no parágrafo $1^{\circ}$ do artigo 144, é a polícia da União que tem competência para apurar a ocorrência de crimes relacionados aos interesses da União Federal e demais crimes que tenham reflexos interestaduais e internacionais, como por exemplo, o tráfico de drogas, o contrabando e o descaminho, além de fiscalizar das fronteiras marítimas e aeroportuárias do Brasil.

Elencada no parágrafo $2^{\circ}$, a polícia Rodoviária Federal é órgão da União encarregado em patrulhar as rodovias federais, do mesmo modo que a Polícia Ferroviária prevista no parágrafo $3^{\circ}$ é a encarregada pela manutenção e fiscalização das ferrovias.
A polícia Civil, também chamada de polícia judiciária estadual, é a polícia que acaba por ficar com a competência de apurar a grande maioria das infrações penais, haja vista que sua atuação é ampla e alcança quase todos os delitos, a exceção dos crimes de competência da Polícia Federal e da Justiça militar. (GALVÃO, 2015, p.1)

Por fim, a polícia militar é o órgão que está mais presente na sociedade, até porque ela se trata da polícia encarregada pela garantia da ordem pública que está nas ruas todos os dias e exerce o trabalho de policiamento ostensivo.

Apesar de se limitar a dispor apenas acerca desses órgãos públicos, sabe-se que a segurança pública abrange ainda outros métodos preventivos de competência do Estado, a fim de se evitar a ocorrência de infrações penais.

Observa-se claramente que, o Estado assumiu a responsabilidade pela segurança dos cidadãos 
brasileiros, competindo a ele a utilização de todas as ferramentas para torna-la mais eficaz e reduzir a

\subsection{DEFINIÇÃO LEGAL}

Em razão do fato de que o dever de garantir a segurança pública é do Estado, admite-se a possibilidade de responsabilizá-lo civilmente quando este não cumprir a sua obrigação.

As simples medidas assistenciais e voluntárias em benefício da população não afastam a responsabilidade do Estado ao responsabilizar civil e penalmente um indivíduo por uma situação em que não conseguiu evitar o conflito. Em razão de se tratar de um estado de direito, o próprio Estado também estará sujeito às regras legais impostas aos demais. (FREITAS, 2008, p.1)

Seguindo esse raciocínio, conforme ensina 0 doutrinador mexicano Luis Rodriguez Manzanera, quando 0 Estado assume a responsabilidade pela segurança pública acaba por assumir também a sua obrigação em reparar eventuais falhas quem venha a ser cometida por ele. (MANZANERA, 1989, p.339)

Em atenção ao fato de que a segurança pública é uma atividade insegurança presente nas cidades brasileiras, frente a alta criminalidade dos dias de hoje.

fundamental na sociedade e que ela compete exclusivamente ao Estado, estará ele obrigado a atuar de forma eficiente na proteção dos administrados e na garantia da ordem pública. Descumprindo tal obrigação, é admita a sua responsabilização. (FREITAS, 2008, p.1)

Essa responsabilidade estatal, conforme estabelece a Constituição Federal, é direta e objetiva, de modo que deverão ressarcir os danos causados por seus órgãos públicos a terceiros.

Contudo, vale salientar que essa responsabilidade somente estará configurada nas hipóteses em que se verificar que a omissão do ente estatal ocorreu por falha na prestação do serviço ou deficiência do mesmo.

Portanto, é constitucionalmente garantido a todos os cidadãos o direito à segurança pública, a qual deverá ser cumprida pelo Estado, sob pena de responsabilização civil em razão de sua omissão. 


\section{RESULTADOS E DISCUSSÃO}

\subsection{A SITUAÇÃO DA SEGURANÇA PÚBLICA EM GURUPI - TOCANTINS}

O mais comum ao andar pelas ruas e assistir aos noticiários locais é a informação de que a violência nesta cidade sofreu um aumento exponencial nos últimos anos, aumentando o pânico de muitos indivíduos em relação à insegurança que se instalou.

Considerando esses comentários, relevante se mostra a apuração de dados e estatísticas locais a fim de verificar se realmente houve o efetivo aumento da violência, ou se está apenas passou a ser observada mais atentamente nos últimos anos, dando a impressão de um caos na segurança pública.

Passa-se agora à uma análise da situação da segurança pública no município de Gurupi, Estado do Tocantins.

\subsection{ESTATÍSTICAS DE FURTOS, ROUBOS E LATROCÍNIOS EM GURUPI DE 2011} A 2015

Diante das cobranças diárias em prol de uma segurança pública mais eficaz é que a Polícia Militar vem apresentando dados oficiais acerca dos índices de violência local, como forma de evidenciar as estatísticas, visando sua melhor atuação no combate à criminalidade.

Segundo $0 \quad 4^{0}$ Batalhão da Polícia Militar do Estado do Tocantins (4ํ BPM/TO), seguem alguns dados estatísticos.

Tabela 1 - Furtos, roubos e latrocínios em Gurupi-TO:

\begin{tabular}{lccccc}
\hline \multicolumn{1}{c}{ Natureza } & Ano/2011 & Ano/2012 & Ano/2013 & Ano/2014 & Ano/2015 \\
\hline Furtos & 801 & 624 & 784 & 741 & 662 \\
\hline Roubos & 266 & 221 & 431 & 623 & 836 \\
\hline Latrocínio & 0 & 0 & 1 & 0 & 2 \\
\hline Total & $\mathbf{1 0 6 7}$ & $\mathbf{8 4 5}$ & $\mathbf{1 2 1 6}$ & $\mathbf{1 3 6 4}$ & $\mathbf{1 4 6 0}$ \\
\hline \multicolumn{7}{r}{ Fonte: Dados fornecidos pelo 40 BPM/TO }
\end{tabular}

Da análise da Tabela 1 percebese que contabilizando os tipos penais de furto, roubo e latrocínio, houve um aumento, haja vista que o ano de 2015 foi o de maior ocorrência dentre todo o período analisado, com o registro total 
de 1460 (um mil, quatrocentos e sessenta) casos de crimes patrimoniais em Gurupi, Estado do Tocantins.

Preocupante esse dado, uma vez que a taxa de roubos foi a maior de todas, demonstrando que os criminosos têm optado pelo uso de violência. Como consequência lógica dos roubos, praticados com violência ou grave ameaça, consiste na dobra de ocorrência de latrocínios, que em 2013 foi de um caso registrado, sendo em 2015 duas ocorrências.

Tabela 2 - Idade dos infratores/autores de furto em Gurupi-TO:

\begin{tabular}{lccccc}
\hline \multicolumn{1}{c}{ Idade } & Ano/2011 & Ano/2012 & Ano/2013 & Ano/2014 & Ano/2015 \\
\hline Menor que 18 anos & 4 & 1 & 3 & 3 & 3 \\
\hline De 18 a 30 anos & 63 & 44 & 53 & 44 & 34 \\
\hline De 31 a 50 anos & 23 & 18 & 20 & 22 & 21 \\
\hline Mais de 51 anos & 2 & 1 & 1 & 1 & 1 \\
\hline Não informado/ignorado & 709 & 560 & 707 & 671 & 603 \\
\hline Total & $\mathbf{8 0 1}$ & $\mathbf{6 2 4}$ & $\mathbf{7 8 4}$ & $\mathbf{7 4 1}$ & $\mathbf{6 6 2}$ \\
\hline
\end{tabular}

Fonte: Dados fornecidos pelo 4 $\mathrm{BPM} / \mathrm{TO}$

Quanto à idade dos autores de crimes, a Tabela 2, demonstra que os furtos são cometidos em sua maioria por agentes entre 18 (dezoito) e 30 (trinta) anos de idade.

Apesar de a sensação ser que os menores infratores serem os mais corriqueiros delinquentes, os dados da Polícia Militar atestam que ocorreram em poucos números, sendo a maior ocorrência em 2011 quando se

Tabela 3 - Idade dos infratores/autores de roubo em Gurupi-TO:

\begin{tabular}{lccccc}
\hline \multicolumn{1}{c}{ Idade } & Ano/2011 & Ano/2012 & Ano/2013 & Ano/2014 & Ano/2015 \\
\hline Menor que 18 anos & 1 & 0 & 2 & 3 & 1 \\
\hline De 18 a 30 anos & 27 & 17 & 30 & 32 & 44 \\
\hline De 31 a 50 anos & 5 & 1 & 6 & 5 & 3 \\
\hline Mais de 51 anos & 0 & 0 & 0 & 0 & 0 \\
\hline Não informado/ignorado & 233 & 203 & 393 & 583 & 788 \\
\hline Total & $\mathbf{2 6 6}$ & $\mathbf{2 2 1}$ & $\mathbf{4 3 1}$ & $\mathbf{6 2 3}$ & $\mathbf{8 3 6}$ \\
\hline
\end{tabular}

Fonte: Dados fornecidos pelo 4ํㅡㄹ BPMTO
Fato é que há uma variação anual no número de furtos praticados no município de Gurupi sendo que em 2011 foi a maior incidência, tendo reduzido em mais de 150 ocorrências novamente, seguido de duas quedas nos anos seguintes no ano seguinte. Já em 2013 aumentou 
Quanto aos registros de roubo, quase que em sua totalidade, não se especificam a faixa etária dos criminosos, sendo que também se apresenta mais corriqueiramente praticado por indivíduos entre 18 e 30 anos, idade mais presente no mundo do crime, sendo o ponto alto da vida criminosa

. Tabela 4 - Idade dos infratores/autores de latrocínio em Gurupi-TO

\begin{tabular}{lccccc}
\hline \multicolumn{1}{c}{ Idade } & Ano/2011 & Ano/2012 & Ano/2013 & Ano/2014 & Ano/2015 \\
\hline Menor que 18 anos & 0 & 0 & 0 & 0 & 0 \\
\hline De 18 a 30 anos & 0 & 0 & 1 & 0 & 0 \\
\hline De 31 a 50 anos & 0 & 0 & 0 & 0 & 0 \\
\hline Mais de 51 anos & 0 & 0 & 0 & 0 & 0 \\
\hline Não informado/ignorado & 0 & 0 & 0 & 0 & 2 \\
\hline Total & $\mathbf{0}$ & $\mathbf{0}$ & $\mathbf{1}$ & $\mathbf{0}$ & $\mathbf{2}$ \\
\hline
\end{tabular}

Fonte: Dados fornecidos pelo $4^{\circ} \mathrm{BPM} / \mathrm{TO}$

Por fim, o crime de latrocínio, felizmente, tem pouca incidência no município de Gurupi-TO. Caracterizado pelo óbito da vítima de roubo, trata-se de um dos delitos com maior reprovabilidade penal, sendo punido com reclusão de 20 a 30 anos, se enquadrando dentre $\mathrm{o}$ rol de crimes hediondos previstos na Lei $\mathrm{n}^{\circ}$. 8.072/1990. Em Gurupi, teve uma ocorrência no ano de 2013, sofrendo aumento de $100 \%$ em 2015, onde foram 2 latrocínios cometidos na localidade.

\subsection{O CASOS EMBLEMÁTICOS DE VIOLÊNCIA NO ANO DE 2015 EM GURUPI-TO}

Os noticiários locais diariamente noticiam a ocorrência de crimes nos mais variados setores do município. Justamente por causa da sua comoção social, alguns dos fatos mais emblemáticos de violência em Gurupi, Estado do Tocantins, merecem destaque no estudo apresentado, posto que se enquadra na questão de segurança pública.
O dia 08 de abril de 2015 marcou a preocupação com a segurança pública em Gurupi com a ocorrência de violência dentro de um prédio público. Nesta data, um homem armado invadiu o Hospital Regional de Gurupi, após ter se envolvido em uma briga em uma conveniência do município, tendo ameaçado os servidores do local para que os mesmos imediatamente iniciassem 0 atendimento de um jovem 
ferido por tiro de arma de fogo. (ALBUQUERQUE, 2015, p. 03)

Poucos dias depois, mais precisamente dia 23 de abril de 2015, foram noticiadas uma série de óbitos decorridos de execuções praticadas nos quatro primeiros meses daquele ano. Até então, já haviam sido 15 mortes registradas, contra o total de 20 do ano anterior. Sobre a criminalidade, Regis Caio mencionou em sua coluna que "em Gurupi, o índice de assassinatos chega a ser alarmante em 2015. Os números dobram se comparamos ao mesmo período de 2014 e 2012 - ano em que teve uma proporção maior de assassinatos na cidade". (CAIO, 2015a, p.05)

Outro crime muito comentado na região circunscreve-se à morte de dois irmãos, violentamente assassinatos em uma conveniência em Gurupi-TO após uma confusão generalizada no local. Inúmeras pessoas receberam através do aplicativo Whatsapp 0 vídeo gravado pelas câmeras de segurança do local, apontando o exato momento da execução das vítimas. $\mathrm{Na}$ época, o delegado responsável pelo caso indiciou dois suspeitos. (COCKTAIL, 2015, p. 03)

Considerando a aglomeração de condenados, vez ou outra, execuções são realizadas dentro de presídios de todo país. No Estado do Tocantins a primeira ocorrência foi no dia 05 de junho de 2015. No Centro de Reeducação Social Luz do Amanhã, a decaptação de dois reeducandos assustou a comunidade, ante a agressividade com que foram retiradas as vidas das vítimas. Segundo se apurou, as mortes foram motivadas por brigas de facções. Pelos homicídios, dois detentos foram indiciados. (CAIO, 2015b, p. 05)

Muitos outros crimes foram divulgados pela imprensa local, todavia, apenas os mais chocantes foram indicados como forma de se evidenciar a proporção do clamor social por segurança pública em Gurupi, sendo a ocorrência de crimes e sua motivação objeto para outra pesquisa jurídica.

\subsection{MEDIDAS EM FAVOR DA SEGURANÇA PÚBLICA DE GURUPI}

Conforme visto anteriormente, a segurança é direito constitucional de todo ser humano em sociedade, sendo incumbência Estatal concorrer para a 
garantia dessa premissa fundamental à preservação de uma vida digna.

Ocorre que atualmente a segurança pública é diariamente colocada em avaliação social dos entes da sociedade civil, sendo debatida em comunidade, fazendo urgir a necessidade de melhor estruturação para aprimorar a segurança pública em toda a localidade.

Recentemente, mais precisamente dia 07 de abril de 2016, a Ordem dos Advogados do Brasil Subseção de Gurupi realizou uma audiência pública para debater questões de segurança pública local.

$\mathrm{Na}$ oportunidade foram feitas explanações da situação da segurança pública neste município por parte das autoridades competentes, sendo ouvidos também representantes da sociedade civil organizada, integrantes do Poder Judiciário, representantes sindicais, entre outros.

Em Gurupi-TO, dentre as maiores questões levantadas destacam-se a necessidade de melhoria na estruturação do sistema penitenciário da região sul, posto que, reeducandos em cumprimento de pena no regime semi aberto, considerando a proximidade e falta de local para $o$ abrigo dos apenados nesse regime, acabam por se deslocar até a cidade para praticar delitos impiedosamente; a urgência em aumento do efetivo das polícias; maior investimento estatal nos aparatos de segurança pública, ante o sucateamento das viaturas e demais equipamentos utilizados pelos policiais; etc. (OAB, 2016a)

Da realização da audiência pública saíram diversos encaminhamentos para a melhoria da segurança pública local, dentre os pedidos citamos 0 uso das tornozeleiras eletrônicas pelos apenados em regime semiaberto quando liberados para a saída temporária; a construção de casas de albergado; a construção de um alambrado em torno do presídio de Cariri do Tocantins, o Centro de Reeducação Social Luz do Amanhã; o aumento do efetivo das polícias; mais viaturas para a realização do patrulhamento em toda circunscrição municipal, etc.. (OAB, 2016b)

Como resultado das solicitações, no dia 05 de maio do corrente ano, a comarca de Gurupi recebeu 100 tornozeleiras eletrônicas para 0 monitoramento dos presos. Dentre elas, 30 serão direcionadas aos reeducandos que prestam serviços à Prefeitura de Gurupi. Outras 50 já 
seriam distribuídas aos apenados beneficiados pela saída temporária do dia das mães. (COCK1, 2016, p.01)

4.4. MECANISMOS PARA A CONSOLIDAÇÃO DA SEGURANÇA PÚBLICA: A RECUPERAÇÃO DO SISTEMA CARCERÁRIO COMO DECORRENCIA DOS DIREITOS HUMANOS

A segurança pública é um problema generalizado, tal como já se evidenciou. Contudo, ante a relevância da matéria tratada é que há que se buscar sempre o aprimoramento dos mecanismos cabíveis para a melhora da convivência social.

A Declaração Universal dos Direitos do Homem estabelece vários direitos fundamentais, sendo que a recuperação do preso é um deles. Mais do que the assegurar as condições mínimas de sobrevivência enquanto custodiado, a providencia dos mecanismos de ressocialização social é necessária, para que o ex condenado tenha direito ao recomeço.

Um dos fatores que, quando bem sucedido, tem contribuído para a segurança social é a reeducação dos detentos através da realização do trabalho, tanto dentro, como também fora do sistema prisional. Promover a integração do condenado é um meio para se reduzir a reincidência e consequentemente a criminalidade, devendo ser este um dos objetivos da administração pública.

Todavia, esse trabalho tem se desenvolvido de forma tímida, merecendo implementos por parte dos integrantes da sociedade civil organizada e também atuação contínua do Poder Público.

É necessária uma reforma drástica no sistema penitenciário nacional e policial, para que se propiciem melhores condições de trabalho aos integrantes da secretaria de segurança pública, garantindo-Ihes o essencial para que desenvolvam com louvor a função de ressocializar os internos.

\subsection{A FORMAÇÃO DE PROMOTORES DE POLÍCIA COMUNITÁRIA EM GURUPI}

Também atingido pela violência generalizada, é que o Centro
Universitário Unirg, em parceria com 0 $4^{\circ}$ Batalhão da Polícia Militar do Estado 
do Tocantins, realizou um Curso para Formação de Promotores de Polícia Comunitária no município de Gurupi.

Objetivando a inclusão da comunidade acadêmica no enfrentamento da questão de segurança pública neste município, o curso contou com a participação de servidores da Unirg, da Universidade Federal do Tocantins (UFT) e do Instituto Federal de Educação, Ciência e Tecnologia (IFTO). (TOCANTINS, 2016b)

Dentre as temáticas abordadas, questões relativas à mobilização da sociedade para estruturar os Conselhos Comunitários; noções de direitos humanos e gestão pela qualidade da Segurança Pública foram

\section{CONSIDERAÇÕES FINAIS}

A Constituição Federal, dentre os direitos fundamentais e sociais, prevê a segurança no caput do art. 5ำ de sua redação, sendo cláusula pétrea, cuja observância é corolário da dignidade da pessoa humana. Assim, a segurança pública é indispensável à manutenção de uma vida saudável em comunidade, sua observância é necessária em todo o território nacional. abordados, tudo em prol de melhorias no sistema municipal, há muito defasado e desestruturado. (TOCANTINS, 2016b)

Dando continuidade ao trabalho iniciado, ainda em maio, será ministrado curso de Agente de Polícia Comunitária para 60 acadêmicos, servidores da Unirg e demais interessados (TOCANTINS, 2016b)

Apesar de inicialmente parecer pouco, o intuito de se preparar agentes, mesmo que comunitários, já se considera um passo em favor da segurança local, sendo certo que a população atemorizada tem procurado meios de reduzir a sensação de insegurança que há anos vem se tornando cada vez maior.

Na última década a questão da segurança pública tem tomado corpo diante das mazelas estatais quanto à omissão do ente público. O aumento da criminalidade tornou este um dos maiores problemas sociais, uma vez que o amedrontamento tomou conta de grande parte da população que tem receio em estar nas ruas ante ao crescimento significativo da violência. 
Como reflexo de toda situação nacional, em Gurupi a situação não é menos preocupante. Segundo apontam os dados fornecidos pelo $4^{\circ}$ Batalhão da Polícia Militar do Estado do Tocantins houve um aumento no índice de crimes cometidos em detrimento do patrimônio da vítima, sendo que o roubo tem aumentado, o que reflete $o$ aumento da violência como um todo.

$\mathrm{O}$ combate à criminalidade é o caminho para a retomada da segurança pública. Mais do que armar nossas polícias, a ressocialização dos apenados é um dos objetivos a se buscar. As oportunidades sociais também devem ser mais concedidas, de modo que o crime não seja visto pela juventude como o meio mais fácil para uma vida com certas regalias.

A criação de políticas públicas em prol da segurança pública é a saída para a reestruturação da segurança em todo Estado do Tocantins. Para tanto, como possuidor da responsabilidade civil de garantia da segurança, ao governo cabe a obrigação de concorrer para dar mais conforto aos cidadãos, equipar os órgãos responsáveis pela segurança pública e promover educação dentre os indivíduos em sociedade

\section{REFERÊNCIAS}

ALBUQUERQUE, Paulo. Sem segurança, homem entra armado e ameaça servidores. Jornal Cocktail, Gurupi, 06 a 10 de abril de 2015. Local. Hospital Regional, p. 03;

CAIO, Régis. A morte à espreita; as execuções continuam. Jornal Cocktail, Gurupi, 23 de abril de 2015a. Geral. Assassinatos em Gurupi, p. 05;

CAIO, Régis. Para a polícia, morte e decaptação de presos em Gurupi é rixa de gangues. Jornal Cocktail. Geral, Gurupi, 12 de junho de 2015b, p. 05;

COCKTAIL, Da redação. Dois irmãos envolvidos em briga são executados sem chance de defesa. Jornal Cocktail, Gurupi, 30 de abril de 2015b. Local. Morte na Conveniência, p. 03;

COCK1. Gurupi recebe tornozeleiras eletrônicas para monitorar presos beneficiados pelo feriado. Publicado em 05 de maio de 2016. Disponível em: < http://cock1.com.br/arquivos/noticias/gurupi-recebe-tornozeleiras-eletronicas-paramonitorar-presos-beneficiados-pelo-feriado/>. Acesso em 06 de maio de 2016;

Conceito de. Segurança Pública. Disponível em: <http://conceito.de/segurancapublica>. Acesso em 26 abr. 2016; 
FREITAS, Marisa Helena D'Arbo Alves de. Segurança pública e responsabilidade do estado pelos danos às vítimas de crimes. In: Âmbito Jurídico, Rio Grande, $\mathrm{XI}$, n. 53, maio 2008. Disponível em: <http://www.ambitojuridico.com.br/site/index.php?n_link=revista_artigos_leitura\&artigo_id=2642>.

Acesso em maio 2016;

GALVÃO, Rodrigo Blanco. Direito Constitucional e Segurança Pública: evolução histórica e análise do atual modelo. Disponível em: < http://rblancog.jusbrasil.com.br/artigos/151841294/direito-constitucional-eseguranca-publica-evolucao-historica-e-analise-do-atual-modelo>. Acesso em: 04 mai. 2016;

LEMOS, Joelson Maciel - Chefe da $2^{\underline{a}}$ seção - Quartel do 4 $\mathrm{BPM} / \mathrm{TO}$. Estatística de Furtos, Roubos e Latrocínios em Gurupi de 2011 a 2015.). Polícia Militar do Estado do Tocantins. Gurupi, 27 de abril de 2016;

MANZANERA, Luis Rodríguez. Victimologia. Estudio de la víctima. 2.ed. México: Porrúa, 1989;

OAB. Ordem dos Advogados do Brasil. Subseção de Gurupi-TO. Em audiência, autoridades discutem medidas para diminuir criminalidade em Gurupi. Publicado em 07 de abril de 2016. Disponível em: <https://www.facebook.com/oabgurupi/posts/1054471817942395>. Acesso em: 05 de maio de 2016;

OAB. Ordem dos Advogados do Brasil. Subseção de Gurupi-TO. Em audiência, autoridades discutem medidas para diminuir criminalidade em Gurupi. Publicado em 07 de abril de 2016a. Disponível em: <https://www.facebook.com/oabgurupi/posts/1054471817942395>. Acesso em: 05 de maio de 2016;

OAB. Ordem dos Advogados do Brasil. Subseção de Gurupi-TO. OAB elabora sugestões sobre segurança pública para apresentar às autoridades. Publicado em 13 de abril de 2016b. Disponível em: < https://www.facebook.com/oabgurupi/posts/1058088977580679>. Acesso em 05 de maio de 2016;

SANTOS, Emerson Clayton Rosa. Conceito de Segurança pública. Disponível em: $<$ http://br.monografias.com/trabalhos2/seguranca-publica/seguranca-publica.shtml>. Acesso em 30 abr. 2016;

SARLET, Ingo Wolfgang. A eficácia dos direitos fundamentais: uma teoria geral dos direitos fundamentais na perspectiva constitucional. 11. ed. rev. atual. Porto Alegre: Livraria do Advogado Editora, 2012;

SILVA, José Afonso da. Curso de Direito Constitucional Positivo. $22^{\underline{a}}$ ed. São Paulo: Malheiros, 2003;

SOUZA, Adelson Joaquim de. Direito Fundamental à Segurança Pública. In: Âmbito Jurídico, Rio Grande, XVIII, n. 133, fev 2015. Disponível em: <http://www.ambito- 
juridico.com.br/site/?n_link=revista_artigos_leitura\&artigo_id=15754>. Acesso em: 30 abr. 2016;

TOCANTINS, Atitude. Curso forma promotores de Polícia Comunitária em Gurupi. Atitude Tocantins, dia 09 de maio de 2016. Disponível em: $<$ http://www.atitudeto.com.br/curso-forma-promotores-de-policia-comunitaria-emgurupi/>. Acesso em 10 de maio de 2016.

Recebido em: 18/05/2016

Aprovado em: 20/09/2017 